\title{
Complexity Analysis on the Influence Factors of the Flight Delay Risk Based on SNA
}

\author{
Yueyao Wang1, Yun $\mathrm{Li}^{2 *}$ \\ ${ }^{1}$ School of Emergency Management, Jinan University, Guangzhou, China \\ ${ }^{2}$ The First Affiliated Hospital of Jinan University, Guangzhou, China \\ Email: *liyun_gz@sohu.com
}

How to cite this paper: Wang, Y. Y., \& Li, Y. (2020). Complexity Analysis on the Influence Factors of the Flight Delay Risk Based on SNA. Open Journal of Social Sciences, 8, 54-71.

https://doi.org/10.4236/jss.2020.85005

Received: April 13, 2020

Accepted: May 10, 2020

Published: May 13, 2020

Copyright $\odot 2020$ by author(s) and Scientific Research Publishing Inc. This work is licensed under the Creative Commons Attribution International License (CC BY 4.0).

http://creativecommons.org/licenses/by/4.0/

\begin{abstract}
Flight delay is the major emergency faced during in the process of flight production guarantee in civil aviation transportation industry, which will cause significant impact on the normal operation of large airports, and the comprehensive management on how to reduce the risk of flight delay has been conducted. Reducing the probability of delay events and its consequences is an important issue and research topics in the emergency management of civil aviation transportation industry. However, large airports are typical complex transportation infrastructure owing to the characteristics of many participation units, complex process, external environmental factors and so on, which decides that the risk factors to trigger flight delay have the characteristics of concealment and diversity, and causes the influence on how to identify the risk factors of flight delay comprehensively and systematically. Secondly, the risk factors of flight delay are interrelated and interweaved for living, which have the typical complexity features and pose the challenges on how to understand the generative mechanism of airport flight delay events and design the risk factors to eliminate and control flight delay events. This paper conducts the in-depth research and analysis of the generative mechanism and law of flight delay events and puts forward design method of flight risk management strategy according to systematic thinking through the in-depth investigation on the flight production guarantee process of Shenzhen Bao'an International Airport (Shenzhen Airport) for the existing problems of the existing flight delay management. Firstly, the analysis on flight production process of Shenzhen Airport based on the theoretical framework of society-ecology-technology is conducted, and it comprehensively uses the web crawler and Delphi method through mixed data collection method. It systematically identifies the risk factors of flight delay and the correlation between risk factors based on the collection of multiple source data of flight delay to form the deep understanding of the generative mechanism of flight delay. In addition, it innovatively uses the social network analysis method to conduct modelling for the
\end{abstract}


risk factors of flight delay and their correlation and carries out analysis on the complexity to put forward risk control strategy from integrity level. The research work of this paper helps the airport management units to have scientific understanding on risk factors of flight delay and their relationship, in order to provide theoretical basis for the scientific design of risk control measures.

\section{Keywords}

Airport, Flight Delay, Risk Governance, Social Network Analysis

\section{Introduction}

With the coming of the era of knowledge economy, China's civil aviation industry, as an important part of transportation industry, ushers in rapid development. As of 2018, the whole industry completes the total transportation turnover amount of 120.653 billion ton kilometers, which is $11.4 \%$ higher than the previous year, with the $611,737,700$ person-times of passenger traffic volume, which is $10.9 \%$ higher than the previous year. Airports are large key traffic infrastructures in cities, as the important parts of air transportation system, and they play an increasingly important role in urban transportation function. At the end of 2018, there are 235 certified transport airports in China. Airport security is an important part of urban public security, which has an important impact to guarantee the normal urban transportation function. Flight delay has an important impact on the normal operation of the airport, which is a major emergency faced by urban local government and the most important emergency faced by urban air transportation service industry. The flight delay situation is extremely serious because of the special management system of airspace. None of the mainland's airlines has entered the top 20 according to the latest "The OAG Punctuality League 2018" released by the aeronautical data company OAG. The "Statistical Bulletin of Civil Aviation Industry Development 2018" in 2018 shows that there are 4.3458 million flights carried out by national passenger airlines in total, including 3.4824 million regular flights with the average flight normal rate of $80.13 \%$. The main airlines carry out 3.1643 million flights in total, including 2.5298 million regular flights with the average flight normal rate of $79.95 \%$. The average delay time of national passenger flights is 15 minutes, which decreases 9 minutes year-on-year. The main situations of flight delay in 2018 are shown in Table 1 and Table 2.

Airport flight delay is an emergency highly valued by civil aviation department, which causes serious influence on normal operation of the airport. How to effectively reduce the probability of flight delay events and reduce negative impact after the happening of flight delay are the top priority of emergency management in civil aviation transportation industry and the key to guarantee the normal provision of transportation services provided by the airport. The basic 
Table 1. Flight delay situation in 2018.

\begin{tabular}{ccc}
\hline Index & Proportion in total & $\begin{array}{c}\text { Increase or decrease over the } \\
\text { previous year: Percentage point }\end{array}$ \\
\hline $\begin{array}{c}\text { Reasons for abnormal } \\
\text { flights of all airlines } \\
\text { Weather reasons }\end{array}$ & $100.00 \%$ & 0.00 \\
Airlines reasons & $47.46 \%$ & -3.83 \\
$\begin{array}{c}\text { Air traffic control reason } \\
\text { (Including flow reason) }\end{array}$ & $21.14 \%$ & 12.52 \\
Others & $2.31 \%$ & -5.42 \\
\hline
\end{tabular}

Table 2. Major airline flight delay situation in 2018.

\begin{tabular}{ccc}
\hline Reasons for abnormal flights of main airlines & $100 \%$ & 0.00 \\
\hline Weather reasons & $48.62 \%$ & -2.85 \\
Airlines reasons & $21.00 \%$ & 11.75 \\
Air traffic control reason (Including flow reason) & $2.75 \%$ & -5.38 \\
Others & $27.63 \%$ & -3.52 \\
\hline
\end{tabular}

way to reduce the probability of flight delay and reduce the impact of flight delay is to comprehensively and systematically identify the risk factors inducing flight delay events, and reduce the risk factors as much as possible based on the analysis of the rules and characteristics of flight delay events. However, the airport regional environment is complex so that the risk factors of flight delay events are diverse, and external environment, facilities and equipment, human behavior, management and other factors may cause flight delay. Secondly, the airport flight delay risk factors have concealment, and the service chain of airport operation process involves multiple resident units. The recognition difficulty of flight delay risk factors is increased due to the diversified risk factors of airport flight delay events contained in the service operation process of different units. Thirdly, there is a complex causal relationship between airport flight delay risk factors, and the emergence of one risk factor will induce other risk factors, so as to lead that multiple flight delay risk factors are interweaved and co-existed with complexity characteristics. The characteristics of the risk factors of the above airport flight delay events bring the challenges for the analysis and development of flight delay risk control measures, which are the problems that must be paid attention to and solved by the resident units in the airport area.

This paper selects Shenzhen Airport as a case for the problems above. It analyzes the law and characteristics by the happening of flight delay, comprehensively and systematically identifies the risk factors of flight delay and the causal relationship between them, and put forwards some diversified risk management measures based on the analysis of the complexity of flight delay risk factors, through the long-term in-depth observation of the operation process and characteristics of Shenzhen Airport. 


\section{Literature Review}

Airports, as the large-scale key transportation infrastructures, have important transport functions, which are the place for people to gather together. At the same time, the normal take-off and landing of flights are easily affected by a variety of internal and external factors, so how to avoid the flight delay has become an important part of airport management. Laskey, Xu, \& Chen (2012), Xu et al. (2009), Shao et al. (2012) used Bayesian network model to gain the mutual influence of risk factors and the affected degree of destination airport respectively to realize the probability prediction of the occurrence and level of flight delay and gain the main factors affecting flight delay in different time periods (Xu et al., 2009; Laskey, Xu, \& Chen, 2012; Shao et al., 2012). Wu Xiping, et al. analyzed the static characteristics of air traffic flow network to put forward overall effectiveness evaluation method of air traffic flow network and built the air traffic delay propagation model based on the cascaded failure model of load capacity and virus propagation model (Wu, Yang, \& Han, 2017). Wang Jinghua, et al. learned from the basic idea of infectious disease model, and analyzed the flight status transition relationship under the situation of large area flight delay to build the large area flight delay propagation model to reflect the change trend of flight delay propagation in large area (Wang, Zhang, \& Ma, 2017) for specific airspace. Zhang Zhaoning, et al. put forward the concept of O-D airport and conducted the analysis on the propagation way of O-D airport delay under large area delay for the spread of large-scale flight delays in this airport and between this airport and the destination airport, which gained the influence of the different routes of propagation on development delay in O-D airport under the situation of large area delay and verify the rationality of the delay propagation model (Zhang \& Wang, 2018). Cao Yueqi, et al. predicted the large-scale flight delay from the perspective of fixed airspace, and gave the prediction method of the number of delayed flights and the accumulated delay time of flights based on the Logistic model (Cao \& Jia, 2017). He Xin, et al. used MATLAB to solve the flight delay data of Shanghai Hongqiao International Airport, and established the large area flight delay recovery model of hub airport, which shows that it is feasible and effective for the methods of recovering large area flight delay in hub airport by using the alternative mode of high-speed railway (He, Gong, Wang, \& Wang, 2018).

In summary, the existing literature lists some factors causing flight delay through classifying the causes of flight delay. At the same time, the existing literature is all about after the flight delay on how to reduce the impact of flight delay in the maximum degree. Owing to the harsh conditions for flight take-off, a lot of equipment and facilities in the airport and intensive personnel, risks cannot be identified accurately, and the existing research can only identify risks through previous cases. This paper introduces the Social Network Analysis method into the complexity analysis process of flight delay risk factors, puts forward the analysis index of complex network of flight delay risk factors and points out the management significance. The control strategy of flight delay risk factors is put forward based on the network analysis results of flight delay risk factors. 


\section{Case Description}

The grade of flight area is indicated by numbers + letters. The first part is number to express the runway length, and " 4 " means more than 1800 meters. The second part is the letters to express the wingspan and wheelbase of an aircraft that can take off and land, which is from $\mathrm{A}$ to $\mathrm{F}$ to become bigger. The $4 \mathrm{~F}$ level airport is one of the highest airport levels. $4 \mathrm{~F}$ class airport representatives can take off and land a variety of large aircraft.

Shenzhen Bao'an International Airport is a $4 \mathrm{~F}$ level civil transport airport located in a coastal plain on the east bank of the Pearl River Estuary, which is 32 kilometers away from Shenzhen City. It covers an area of 451,000 square meters, has runway $(3400 \mathrm{~m} \times 45 \mathrm{~m})$, one taxiway and the total area of terminal building of 195,000 square meters, which can meet the requirement of annual passenger throughput of 45 million. In recent, The Shenzhen Airport throughput has been increasing. In 2018, there are 356,000 take-off and landing flights at Shenzhen Bao'an International Airport with up $4.6 \%$ year-on-year. At the same time, the passenger throughput is 49.349 million with up $8.2 \%$ year-on-year, and the growth rate ranks first among the top ten airports in Mainland China. Passenger throughputs of Shenzhen Bao'an International Airport in 16 - 18 years are shown in Table 3 (Luo, 2018). As one of China's five major airports, Shenzhen Bao'an Airport has a huge flow of people and has multiple attributes such as sociality and economy.

Definition of flight delay: The "Regulations on normal flight management" sets that flight delay refers to the situation that the landing time of the flight (the chock-to-chock time of the actual arrival of flight) is more than 15 minutes later than scheduled landing time (time on flight schedule) or flight cancellation.

Definition of large area flight delay: According to the emergency plan of Shenzhen Bao'an International Airport, when the special weather, flow control, airport equipment and facilities failure, airport closure and other factors cause large-scale flight delays in Shenzhen Bao'an International Airport, and when the number, properties, severity, controllability and impact scope of flight delay satisfy the conditions of emergency response plan for flight delay, the emergency response plan for large area flight delay of different levels shall be launched.

When one or more of the following conditions occur, it is the lowest standard to launch the large area flight delay response:

1) The departure flights delayed for more than one hour are more than $10 \%$ of the scheduled departure flights of that day.

2) When the number of passengers detained in the terminal building reaches 6500 .

3) The implementation rate of departure flights is less than $50 \%$ for more than 2 hours in a row in the peak hours (08:00-23:00) (Departure flight execution rate $=$ Scheduled departure flights in one hour period/Scheduled departure flights for the period).

4) The airport has no flights for landing or take-off for more than one hour but less than one hour and 30 minutes in peak hours (08:00-23:00). 
Table 3. Passenger throughput of Shenzhen Bao'an International Airport in 16 - 18 years.

\begin{tabular}{cc}
\hline Year & Passenger throughput (Unit: 10,000 person times) \\
\hline 2016 & 4197.5 \\
2017 & 4561 \\
2018 & 4934.9 \\
\hline
\end{tabular}

5) If the airport AOC considers to start the plan according to flight operation and overall consideration of the actual situation of each operation support unit, it shall be agreed by the company operation director. Airlines need to coordinate the release of delayed flights in time, conduct service coordination for passengers, release information for others, report weather conditions, and contact the rescue team when it is necessary. The logistics support department shall supply the materials and guarantee the traffic of the rescue team.

\section{Data Collection Method}

1) Archival method: Get the list of flight delay risk factors to ensure the reliability of data according to collection of flight delay cases in recent years and summary of risk factors leading to flight delay.

2) Interview method: Have deeper understanding on the factors that may cause flight delay to further guarantee the reliability of research through field investigation, and the interview with the staff in the airport to find out the missing.

3) Delphi method: Through questionnaire surveys and methods discussed by experts, the collected data is sorted out, and the issues to be studied are judged and predicted. Based on past cases and analysis of the staff inside the airport, the relationship between the risk factors that caused flight delays was obtained.

4) Workshop method: Through the methods discussed by the airport staff and experts, the collected data is sorted out and guidance is provided to ensure the reliability of the study.

\section{Risk Factors of Flight Delay and Its Relevance Identification}

Flight delay is the most important emergency faced by airport area operation. Identifying the complex risk factors of flight delay is the basis and premise of reducing the probability of flight delay by eliminating the risk factors. In addition, the risk factors of flight delay are not independent. The complex relevance led by causal relationship between risk factors is one of the root causes of flight delay events that are difficult to control. At the same time, the identification of risk factors and their relationship cannot be completed by a single department, so it needs multiple departments to participate and identify together. This chapter starts from the analysis and characteristics of regional operation process and Shenzhen Airport to conduct interview with staff of all departments inside and outside the airport, which will make people fully identify the risk factors of flight 
delay in Shenzhen Airport, through methods of expert interview. On this basis, the causal relationship of the risk factors of flight delay is determined and identified, which can understand the complexity of airport flight delays more intuitively and lay the foundation for the analysis and design based on complexity and formulating risk control measures.

\subsection{Identification Method of Airport Flight Delay Risk Factors}

Conduct the interviews with airport staff and experts through the statistical analysis of previous cases. At present, Chinese scholars' recognition of the causes of flight delay can be mainly divided into the following categories: The first is that the factors causing flight delay are divided into five categories by Liu Yu and other scholars, which include airline reasons; airport security reasons; aviation control reasons; weather reasons; passenger reasons and other reasons (Liu, 2014). This classification method is quite common, which basically covers all possible causes leading flight delay at the same time. Among them, Ma Yu divides the causes of flight delay into two big categories based on this classification method. The one is airlines' own factors including inadequate maintenance, unreasonable flight allocation and so on; The other is not airlines' own factors including weather factors, air control, mechanical failure, passengers' own factors and so on (Ma, 2010). The second is Zhu Shupeng's suggestion that there are two kinds of factors that cause flight delay: One is an objective factor that is irresistible or cannot be changed in a short time due to the influence of the environment; The other is to change the subjective factors through enterprise and official efforts, and adopting various new technologies, new procedures, new systems and other measures ( $\mathrm{Zhu}, 2013)$. The third classification method was proposed by Ma Zhengping and Cui Deguang in 2004 to conduct the analysis on the flight delay from the macro and micro perspectives. In the macroscopic aspect, the main factors affecting flight delay is the capacity of the airport and the relevant airspace. In the microscopic aspect, the main factors affecting flight delay is weather, aircraft breakdown, airline plans, passengers and so on respectively (Ma \& Cui, 2004).

The risk factors causing flight delay are complex and diverse with characteristics of diversity, concealment and complexity, which cannot be recognized directly. Therefore, the first task is to identify the risk factors of flight delay. This paper uses the web crawler software, Delphi method and the method of expert interview to conduct the identification for risk factors of flight delay. Firstly, the risk factors of flight delay are extracted through the released information by the official news platform of the central government and all regions, keyword system query, cross validation of multiple media channels and other methods to conduct the collection and screening of flight delay description text, through interviews with Delphi and experts, five staff members from key departments of the flight production support business process (including Shenzhen Bao'an Airport

Operation Command Center, China Southern Airlines and ground handling service department) were invited to address the actual situation and flights of 
Shenzhen Airport The actual production process is compared with the risk factor checklist constructed in the second step to screen, identify, confirm and supplement the risk factors of flight delays at Shenzhen Airport, and finally form a list of risk factors for flight delays at Shenzhen Airport.

This paper uses the MMEM model of "human-machine-environmentmanagement" commonly used in China's civil aviation industry to conduct classification which is shown in Figure 1. This model develops from the idea of Human, machine and environment put forward by White in Cornell University in 1940s and the relationship model among human, machine and environment with management as the boundary proposed by Kanti and others of New York Institute of Technology ( $\mathrm{Du} \& \mathrm{Wu}, 2014)$. Finally, it is divided into four categories including human factors, equipment and facilities factors, environmental factors and management factors, which have relationship of mutual influence. These four factors include 49 risk factors of flight delay, which are shown in Table 4:

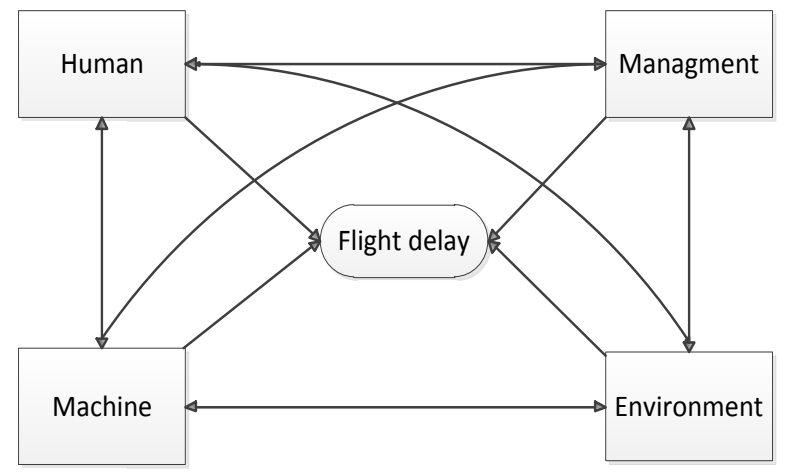

Figure 1. MMEM model of flight delay risk.

Table 4. Risk factors of flight delay in Shenzhen Bao'an International Airport.

\begin{tabular}{lll}
\hline Number & Risk factor & Risk types \\
\hline F1 & Flight delay & \\
F2 & Artificial damage to aircraft & Human \\
F3 & Bomb threats & Human \\
F4 & Passenger refused to board & Human \\
F5 & Due to the passenger's own certificate, safety check, Luggage & Human \\
F6 & transportation check-in and other issues, the boarding is delayed & \\
F7 & Fare evasion of passengers & Human \\
F8 & Aircrew are late & Management \\
F9 & Aircrew deployment & Management \\
F10 & Aircrew management vulnerability & Management \\
F11 & Fire in airport & Management \\
F12 & Boarding bridge accident & Human
\end{tabular}




\section{Continued}

\begin{tabular}{|c|c|c|}
\hline F13 & Airport security vehicle accident & Machine \\
\hline F14 & Failure of communication and navigation facilities & Machine \\
\hline F15 & Power failure & Machine \\
\hline F16 & Airport power facilities failure & Machine \\
\hline F17 & Runway light failure & Machine \\
\hline F18 & Network failure & Machine \\
\hline F19 & Check-in system failure & Machine \\
\hline F20 & Visual aid facilities failure & Machine \\
\hline $\mathrm{F} 21$ & Aviation oil accident & Machine \\
\hline $\mathrm{F} 22$ & Security vehicle oil accident & Machine \\
\hline F23 & Meteorological facilities failure & Machine \\
\hline $\mathrm{F} 24$ & Aircraft monitoring facilities failure & Machine \\
\hline F25 & Accidents between aircraft and vehicle & Machine \\
\hline F26 & Accidents between aircraft and aircraft & Machine \\
\hline F27 & Blowout of aircraft tire & Machine \\
\hline F28 & Smog & Environment \\
\hline F29 & Fog & Environment \\
\hline F30 & Rainstorm & Environment \\
\hline F31 & Thunderstorm & Environment \\
\hline F32 & Low cloud & Environment \\
\hline F33 & Bird pest & Environment \\
\hline F34 & Fierce wind & Environment \\
\hline F35 & Typhoon & Environment \\
\hline F36 & Jamming of artificial laser transmitter in flight protection area & Human \\
\hline F37 & Playing unmanned aerial vehicle in the clearance area & Human \\
\hline F38 & Flying kites in the clearance area & Human \\
\hline F39 & Kongming latern burned in the clearance area & Human \\
\hline $\mathrm{F} 40$ & Fireworks burned in the clearance area & Human \\
\hline F41 & Machine maintenance cause & Management \\
\hline F42 & Reasons for aircraft maintenance & Management \\
\hline $\mathrm{F} 43$ & Too much traffic at the security office & Management \\
\hline F 44 & Military exercise & Management \\
\hline F45 & Runway seeper & Environment \\
\hline F46 & Flow control & Management \\
\hline F47 & The flight arrived late & Management \\
\hline $\mathrm{F} 48$ & Aircraft deployment & Management \\
\hline F49 & Mechanical failure & Management \\
\hline
\end{tabular}




\subsection{Identification Method of Risk Factors Relationship of Airport Flight Delay}

The risk factors of flight delay are diverse. Secondly, risk factors are related with each other with complex causal relationship. Any factor may lead to occurrence of other risk factors, so it is necessary to determine the causal relationship between flight delay risk factors. The relationship between risk factors of flight delay is determined through Delphi method and the method of expert interview, and the main determination criteria are whether the risk F1 will lead to risk F2. If it can cause, fill in 1 in the form, and if it cannot cause, fill in 0 in the form. Thus, the relationship table on risk factors of airport flight delay can be obtained (see Annex 2 for the relationship between flight delay risk factors of Shenzhen Airport). From the data in the risk factor relationship table, we can get the mutual influence relationship between the risk factors of flight delay, which is shown in Figure 2.

\section{Complexity Analysis Based on the Risk Factors of Flight Delay of SNA}

Urban airport area, as a complex area with high density of people flow, material flow and aircraft flow, exist various risk factors inducing flight delay during the process of operation with high relevance between risk factors. This chapter introduces the Social Network Analysis method into complexity analysis process of flight delay risk factors to put forward analysis index of complex network of flight delay risk factors and point out management significance based on the identification of the flight delay risk factors and its correlation relationship in Shenzhen airport. On this basis, the control strategy of flight delay risk factors is put forward based on the network analysis results of flight delay risk factors.

\subsection{Network Analysis Method of Flight Risk Factors Based on SNA}

\section{1) Centrality analysis of point degree}

Degree centrality is the most direct measure to describe node centrality in network analysis. The greater the degree of a node, the higher the centrality of the node degree, and the centrality of node degree indicates the direct relationship between risk factors. The formula for measuring degree centrality is as follows:

$$
C_{D}^{\prime}\left(N_{i}\right)=\frac{C_{D}\left(N_{i}\right)}{g-1}
$$

In this standardized centrality measurement formula, divide the node degree centrality value of node $i$ by the maximum possible number of connections of other $g-1$ nodes to get the proportion of network nodes directly related to node $i$ (Liu, 2009).

In the network figure, the node degree can be divided into in-degree and out-degree. The degree centrality of nodes indicates the direct relationship between risk factors. In the network of flight delay risk factors, the node with 


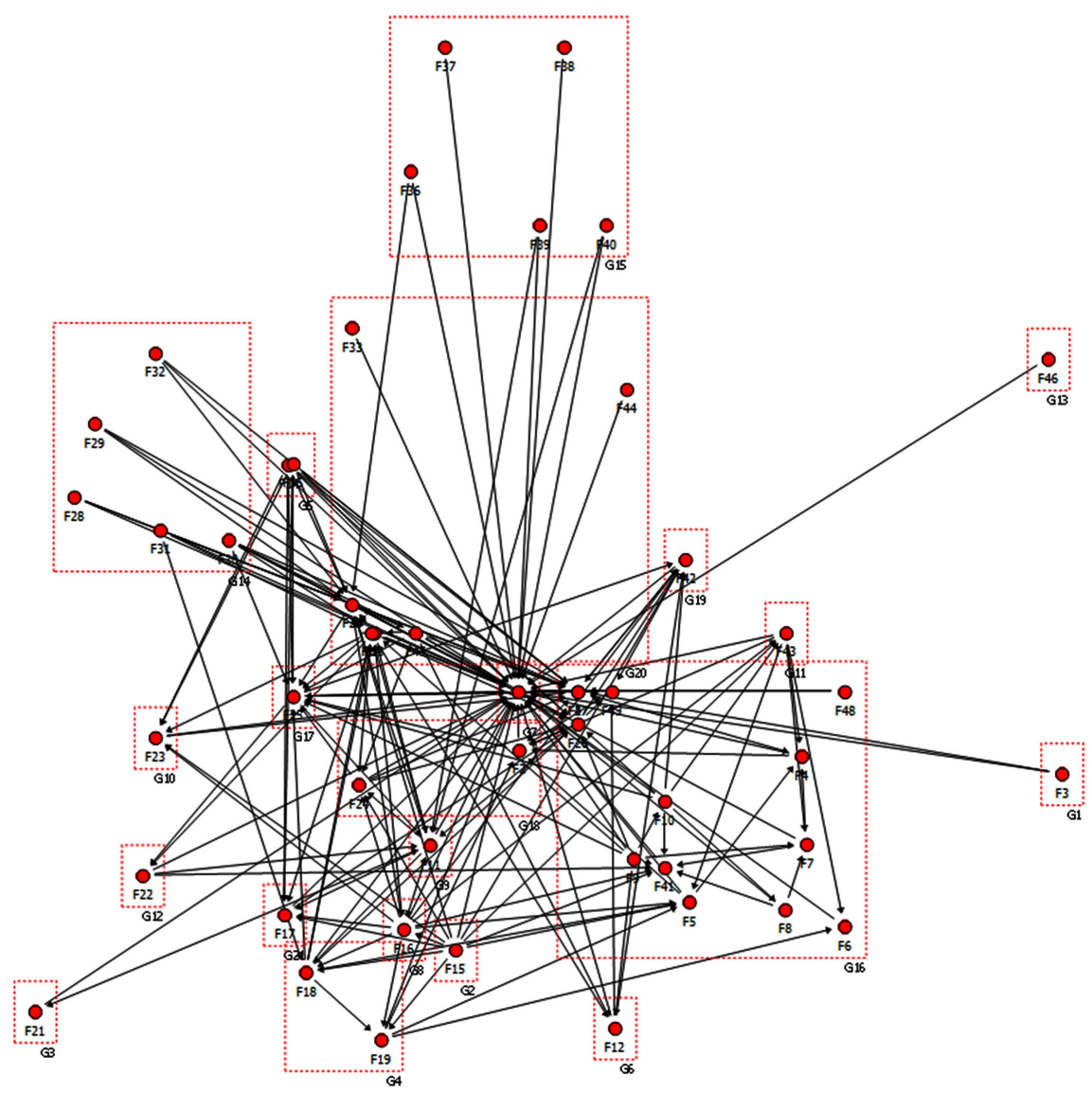

Figure 2. Relationship networks of risk factors of flight delay.

higher in-degree centrality shows that these risks are affected by more other risks, and the node with higher out-degree centrality shows that there are many other risk factors affected by these risk factors. The node with higher in-degree and out-degree shows that these risk factors are not only affected by many other risks, and there are many other risk factors.

\section{2) The analysis of betweenness centrality}

The betweenness centrality of point refers the degree to which points are "in the middle" of other nodes in the network figure, so as to measure the ability to interact with other risk factors in the risk node control network (Abbasi \& Kapucu, 2012). The higher the betweenness centrality of a node, the stronger the influence of this risk factor on other risk factors transmitted through it, which has the critical status in network figure.

\section{3) The analysis of closeness centrality}

The closeness centrality refers to the shortest distance between one node and other nodes (Faraj \& Xiao, 2006). The closer the distance between one node with other nodes, the higher the closeness centrality. When a node has closeness centrality, this node has no direction in the network, but in the directional network, the node with closeness centrality needs to expand. In-closeness centrality and out-closeness centrality are gained through the analysis results of closeness centrality. The higher the in-degree of a node is close to centrality, it means that this 
risk factor is more easily affected by other risk factors. The greater the outgoing degree of a node is to centrality, the more likely this risk factor will affect other risk factors. The closeness centrality in the risk factor networks is defined as the sum of in-closeness centrality and out-closeness centrality.

$$
C(\chi)=\frac{1}{\sum_{\gamma} d(\gamma, \chi)}
$$

\section{4) Block analysis}

In the overall risk network, risk factors are considered as points, and the risk factors in the same type are considered as blocks. Therefore, the risk network block analysis is a research at the level of risk type, it can provide links between risk types to realize the simplification of network, which is more conducive for us to describe the overall characteristics of the network. Clustering density of each block and the density of the whole network are compared according to density index method by using Netminer to analyze. When the clustering density is bigger than overall network density, it shows that this sub matrix is closely related and has good clustering effect, so it is determined that the sub matrix is 1-block. When the matrix density is smaller than overall network density, it shows that this sub matrix is 0 -block.

\subsection{Network Construction of Flight Delay Risk Factors in Shenzhen Airport}

Based on the third chapter of this paper to identify the risk factors of flight delay and risk factors relationship, the risk factors network relationship of flight delay is built through workshop method by taking Shenzhen Bao'an International Airport as the analysis object. If one risk factor Fi will directly lead to the occurrence of another risk factor $\mathrm{Fj}$, the risk relationship between them is represented by " 1 " or it will be represented by " 0 ". The network relationship of risk factors of flight delay shall be further confirmed and corrected through the methods of making discussion with airport operation command center, airport emergency office and many experts of airline crew. A total of 49 risk factors and 197 causal relationships are identified. The mutual influence relationship of risk factors are determined by 4.3 using social network analysis tools Netminer to let risk factors network relationship of flight delay become visible.

\subsection{Analysis Result}

The mutual influence relationship between the risk factors of flight delay is achieved in this paper through the analysis on relationship network of risk factors of flight delay in Shenzhen Bao'an International Airport, which lay a foundation for the Shenzhen Bao'an International Airport to formulate flight delay risk management strategy. This chapter takes Shenzhen Bao'an International Airport as a specific bearing body and the risk factor network describes the relationship between risk factors in detail. This chapter uses social network analysis tools Netminer to let risk factors network relationship of flight delay become 
visible, which is shown in Figure 2. In the figure of risk relationship network, we can see that the risk factor is the node in the network with 49 nodes in total in the list of risk factors of flight delay gained by the 3.1 of the paper.

As shown in Figure 2, node F1 (flight delay) has no output relationship named as endpoint. Other nodes with inputs and outputs describe the process of mutual influence among risk factors. It can be seen that the source node leads to the occurrence of flight delay finally through affecting multiple risk factors through. Therefore, controlling and eliminating the node with the shortest input flight delay path can better control the occurrence probability of flight delay.

\subsubsection{Centrality Analysis Results}

\section{1) Degree centrality of flight delay risk factors}

This chapter uses in-degree centrality and out-degree centrality to represent the controllability of risk factors, and in all nodes, the top 5 nodes of in-degree centrality and out-degree centrality are shown in Table 5.

According to Table 5, the occurrence of arrived late of flight, accidents between aircraft and aircraft, accidents between aircraft and vehicle, fire in airport, visual aid facilities failure and other risk factors are difficult to control. Therefore, when designing risk factor control and elimination strategies, it is necessary to consider the risk factors located in the front list at first.

\section{2) Betweenness centrality of flight delay risk factors}

In the network of flight delay risk factors, the nodes at the betweenness centrality are the important factors to control the transmission of risk factors. When the nodes with high betweenness centrality are controlled, it will reduce the probability of occurrence of other risk factors. The top 5 of the risk factors of betweenness centrality are shown in Table 6 .

In the list of the risk factors in Table 6, the top 5 of the risk factors of betweenness centrality plays a key role in the transmission process of risk factor network. If these risk factors (such as fire in airport, artificial damage to aircraft, accidents between aircraft and vehicle, accidents between aircraft and aircraft, airport power facilities failure and so on) are removed from the risk factor network, it will reduce the probability of occurrence of other risk factors so that it can reduce the probability of occurrence of flight delay

\section{3) Closeness centrality of flight delay risk factors}

In the risk factors network of flight delay, the nodes with high closeness centrality shows that the risk factors of nodes play an important role in the whole risk factor network, which are the first risk factors needed to be controlled and eliminated. The top 5 of the risk factors of closeness centrality are shown in Table 7 .

As shown in Table 7, in the risk factors, accidents between aircraft and vehicle, accidents between aircraft and aircraft, fire in airport, airport power facilities failure and arrived late of flight play important roles in the network of flight delay risk factors, which is the risk factors that need to be cut off and solved first when we design elimination strategy of risk factor. 
Table 5. Degree centrality of flight delay risk factors of Shenzhen Bao'an International Airport.

\begin{tabular}{cccc}
\hline Serial number & Risk factor & Number & Degree centrality \\
\hline 1 & The flight arrived late & F47 & 0.395833 \\
2 & Accidents between aircraft and aircraft & F26 & 0.375 \\
3 & Accidents between aircraft and vehicle & F25 & 0.375 \\
4 & Fire in airport & F11 & 0.333334 \\
5 & Visual aid facilities failure & F20 & 0.333333 \\
\hline
\end{tabular}

Table 6. Betweenness centrality of risk factors of flight delay in Shenzhen Bao'an International Airport.

\begin{tabular}{cccc}
\hline Serial number & Risk factor & Number & Betweenness centrality \\
\hline 1 & Fire in airport & F11 & 0.196011 \\
2 & Artificial damage to aircraft & F2 & 0.125172 \\
3 & Accidents between aircraft and vehicle & F25 & 0.107606 \\
4 & Accidents between aircraft and aircraft & F26 & 0.09766 \\
5 & Airport power facilities failure & F16 & 0.085607 \\
\hline
\end{tabular}

Table 7. Closeness centrality of risk factors of flight delay in Shenzhen Bao'an International Airport.

\begin{tabular}{cccc}
\hline Serial number & Risk factor & Number & Closeness centrality \\
\hline 1 & Accidents between aircraft and vehicle & F25 & 0.644422 \\
2 & Accidents between aircraft and aircraft & F26 & 0.642397 \\
3 & Fire in airport & F11 & 0.609477 \\
4 & Airport power facilities failure & F16 & 0.594186 \\
5 & The flight arrived late & F47 & 0.586842 \\
\hline
\end{tabular}

\subsubsection{Block Analysis}

Risk factors that cause flight delays have diverse and hidden features. Therefore, this paper divides the risk factors of flight delay into four categories: "Human, Machine, Environment and Management". These four kinds of risk factors have mutual influence. The number of four categories of risk factors is 11, 16, 9, 12, which are shown in Figure 3. The clustering density of types of the risk factors of flight delay and the density of the whole network are compared according to the density index method and using the Netminer analysis tools. When the sub matrix is 1-block, it shows that the two types of risk are closely related and when the sub matrix is 0-block, it shows that the two types of risk are not closely related. It is shown in Table 8. 


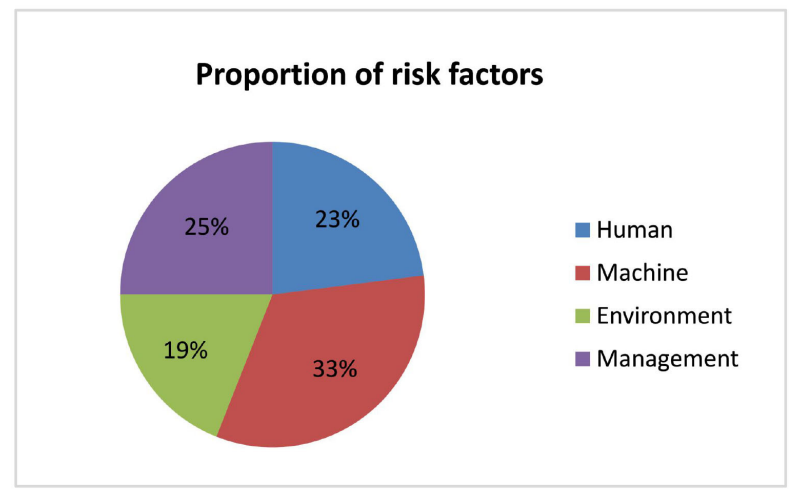

Figure 3. Proportion of risk factors.

Table 8. Block matrix of flight delay risk types of Shenzhen Bao'an International Airport.

\begin{tabular}{ccccc}
\hline & Human & Machine & Environment & Management \\
\hline Human & 0 & 0 & 0 & 1 \\
Machine & 0 & 1 & 0 & 1 \\
Environment & 0 & 1 & 0 & 1 \\
Management & 0 & 0 & 0 & 1 \\
\hline
\end{tabular}

Through risk type block matrix table, Ucinet tools are used to get the network figure, and we can see that the unsafe behaviors of people will lead to internal management problems of airports; The unsafe state of facilities and equipment will influence the safe state of other facilities and equipment and lead to risk factors of airport management type; Changes in the environment will cause damage or failure of facilities and equipment and lead to risk factors of management type; The risk factors of management type will also cause other risk factors of management type. From the analysis above, we can see that the unsafe state of facilities and equipment will cause the occurrence of two kinds of risk factors. Therefore, it is the main task of risk control to ensure normal operation of facilities and equipment.

\subsection{Risk Control Strategy Design Based on Risk Factor Network Analysis}

The seven factors that the arrived late of flight, accidents between aircraft and aircraft, accidents between aircraft and vehicle, fire in airport, airport power facilities failure, visual aid facilities failure and artificial damage to aircraft are risk factors that need to be solved first in airport risk control strategy design. At the same time, the risk factor belonging to the risk type of facilities and equipment is the risk factor needed to be controlled first through block analysis, so accidents between aircraft and aircraft, accidents between aircraft and vehicle, airport power facilities failure and visual aid facilities failure belongs to the risk type of facilities and equipment, which shall be controlled first. 
1) Regulate the driving of vehicles in the flight area

In the flight area, it exists the aircraft tractor, aircraft cleaning vehicle, airplane food truck, luggage cart, shuttle bus for passengers, corridor bridge car for airplane in the far position, airport staff vehicles, runway patrol car and other vehicles. In the flight area, it is necessary to limit the speed of vehicles to less than 30 per hour during the operation of runway patrol car to avoid the traffic accidents in the flight area. At the same time, the paths and directions of vehicles and aircrafts in the flight area need to be marked with different pigments to avoid the driver's difficulty in identifying.

2) Cease the maintenance frequency of designated facilities and equipment in the airport

The normal operation of power facilities and visual aids in the airport is the important factors to ensure the normal operation of airport. Sufficient emergency power supply is required, in the aspect of power facilities, to ensure that when airport power facilities fail, the emergency power can keep the operation of airport to some extent. Secondly, it is necessary to have replacement and inspection of old power facilities, and it can be placed at the location of power facilities in high risk areas when it is necessary. Thirdly, if the visual aid facilities are in open air, it is necessary to increase the number of on-site inspection, and at the same time, emergency navigational lights shall be prepared to ensure the successful take-off and landing of aircraft under the situation of power failure or equipment damage.

3) Protection of aircraft safety

The artificial damage to aircraft is extremely dangerous. Therefore, in a conspicuous place on a ticket or airport, it shall add the slogan on forbidding touching and destroying the aircraft. At the same time, it is necessary to monitor the passengers in the flight area. If the passengers have abnormal behaviors or actions, airline staff should stop the behaviors. If passengers damage the aircraft, they shall be severely punished.

4) Prevention of the occurrence of fire

Airports need to pay more attention to the protection and monitoring of flammable and explosive areas with sufficient fire-fighting materials, and check the use situation of fire-fighting materials regularly. At the same time, it is necessary to keep close contact with fire department to ensure the stable water pressure of fire hydrant to prevent the water from running out of fire hydrant in case of fire. If there is no water supply on that day, the airport shall prepare enough fire water or other items.

5) Reasonable scheduling

When the flight delay will happen due to weather, air traffic control department needs to accurately predict the departure place, destination place and weather conditions of the route, and arranges the flight schedule reasonably. When the weather gets better, the aircraft can be arranged the take-off in time to avoid the chain effect, which will lead to the aircraft queuing. 


\section{Conclusion}

This article introduces the social network analysis (SNA) method from a holistic level, introduces the complexity analysis process of flight delay risk factors, and proposes analysis indicators of the complex network of flight delay risk factors, from the centrality and block model analysis from the perspective of the flight delay risk factor network. It is proposed that among the risk factors of flight delays, aircraft and aircraft traffic accidents, aircraft and vehicle traffic accidents, airport power facility failures, and visual navigation aids failures are the risk factors that airports need to control first.

\section{Conflicts of Interest}

The authors declare no conflicts of interest regarding the publication of this paper.

\section{References}

Abbasi, A., \& Kapucu, N. (2012). Structural Dynamics of Organizations during the Evolution of Interorganizational Networks in Disaster Response. Journal of Homeland Security and Emergency Management, 9, 21. https://doi.org/10.1515/1547-7355.1975

Cao, Y. Q., \& Jia, Q. (2017). Research on Prediction Method of Large Area Flight Delay Based on Logistic Model. Journal of Transport Information and Safety, 35, 86-91.

Du, H. B., \& Wu, J. (2014). Analysis of the Factors Influencing the Risk of Foreign Objects in Airport Based on MMEM-ISM Method. Journal of Safety and Environment, 14, 8-11.

Faraj, S., \& Xiao, Y. (2006). Coordination in Fast-Response Organization. Management Science, 52, 1155-1169. https://doi.org/10.1287/mnsc.1060.0526

He, X., Gong, X. X., Wang, C. Z., \& Wang, K. (2018). Research on Flight Delay Recovery Model of Hub-Airport. Science Technology and Industry, 18, 124-127.

Laskey, K. B., Xu, N., \& Chen, C. H. (2012). Propagation of Delays in the National Airspace System. In The Proceedings of 22nd Conference on Uncertainty in The Artificial Intelligence (pp. 265-272). Chongqing: Computer Science.

Liu, J. (2009). Lecture Notes on Overall Network Analysis: UCINET Software User Guide. Shanghai: Gezhi Publishing House.

Liu, Y. (2014). Reasons on Flight Delay Reasons and Solutions. Public Communication of Science \& Technology, 6, 41+38.

Luo, Y. Z. (2018). Passenger Throughput of Baoan International Airport 50 million in 2018. Baoan Daily.

http://ibaoan.sznews.com/content/2019-01/21/content_21361845.htm

Ma, Y. (2010). Analysis on the Causes of Flight Delay and Countermeasures. Market Modernization, No. 26, 217.

Ma, Z. P., \& Cui, D. G. (2004). Optimization Model of Airport Flight Delay. Tsinghua Science and Technology (Natural Science Edition), No. 4, 474-477+484.

OAG. The OAG Punctuality League 2018 (2018). https://www.useit.com.cn/thread-17671-1-1.html

Shao, Q., Luo, X., Wu, K. K., \& Han, S. C. (2012). Analysis of Airport Flight Delay Factors Based on Bayesian Networks. Science Technology and Engineering, 12, 8120-8124. 
Statistical Bulletin of Civil Aviation Industry Development 2018 (2018). http://www.caac.gov.cn/XXGK/XXGK/TZTG/201905/t20190508_196035.html

Wang, J. H., Zhang, Z. N., \& Ma, L. (2017). Research on the Propagation of Large Area Flight Delay Based on SIR Model. Aeronautical Computing Technique, 47, 41-44.

Wu, X. P., Yang, H. Y., \& Han, S. C. (2017). Air Traffic Characteristics and Delay Propagation Analysis Based on Complex Networks. Acta Aeronautica ET Astronautica Sinica, 38, 113-119.

Xu, T., Ding, J. L., Wang, J. D., \& Zhao, X. J. (2009). Model for Flight Delays and Analyzing Delay Propagation Based on Bayesian Networks. Journal of System Simulation, 21, 4818-4822.

Zhang, Z. N., \& Wang, J. H. (2018). The State Space Model of the Propagation of Large Area Flight Delay in Airports. Science Technology and Engineering, 18, 241-245.

Zhu, S. P. (2013). The Exploration on the Cause Analysis and Countermeasures on Domestic Flight Delay. Journal of Weifang University, 13, 118-120. 